\title{
Entre Cuba y las Azores: imágenes y percepciones en las relaciones entre España y los Estados Unidos
}

\author{
Between Cuba and the Azores: images and \\ perceptions in relations between Spain and \\ the United States
}

José Luis Neila Hernández*

Resumen

Las imágenes y percepciones entre norteamericanos y españoles han estado determinadas por el curso de sus relaciones bilaterales, su propio devenir en la sociedad internacional -una potencia emergente y una potencia eclipsada- y la naturaleza de sus propias sociedades. Hitos históricos como la guerra de 1898, los pactos con Estados Unidos desde 1953 o el anclaje europeo y atlántico de la España democrática ponen en evidencia las imágenes y los sentimientos encontrados entre ambos pueblos. Un cruce sobre el que confluyen actitudes antiamericanas de diferentes tradiciones político-ideológicas españolas y la realidad de la americanización -modernización- de la sociedad española en el fluir del siglo XX.

Palabras Clave: historia, España, Estados Unidos de América, historia de las relaciones internacionales, política exterior

Abstract

The images and perceptions between North American and Spanish people have been determined by the evolution of their bilateral relations, their own evolution within the international society-an emergent power and one in decline-and the nature of the relevant. Historical milestones

Catedrático de la Universidad Autónoma de Madrid, <jlneila@hotmail.com>. Recibido el 23 de abril de 2008; aceptado el 12 de junio 2008. 
such as the War of 1898, the agreements with the United States of America from 1953 or the European and Atlantic alignment of democratic Spain show the images and conflicting feelings between both countries. A crossroads anti american attitudes originating in different political and ideological traditions and the reality of the americanization-modernization- of the Spanish society throughout the $20^{\text {th }}$ century converge.

Key Words: history, Spain, United States of America, world politics, foreign policy. 
Las imágenes de Cuba y las Azores en el trasiego de un siglo de relaciones hispano-norteamericanas evocan en dos hitos cronológicos de signo muy diferenciado el pálpito de sus recíprocas experiencias transatlánticas. Cuba revierte no solo sobre el único episodio bélico entre ambos Estados sino que transciende sobre los componentes de la crisis finisecular al hilo de la cual se evaporarían los últimos residuos del imperio americano-pacífico de España. 1898 y Cuba, en la iconografía española, encarnan el «Desastre» y el desclasamiento internacional de España. La imagen de las Azores el 16 de marzo de 2003, del trío de las Azores -Georges Bush, Tony Blair y José María Aznarencarna, por su lado, el cenit emocional del componente atlantista que ha polarizado, junto a su dimensión europea, el redireccionamiento de la política exterior española desde mediados del siglo XX. Si 1953 cristalizaba el fin de una larga tradición neutralista respecto a los grandes asuntos mundiales y la incardinación atlantista de España, la foto de las Azores retrata el extremo de la pendiente en la deriva atlantista, que junto con el componente europeísta conformaron los cimientos de la homologación internacional de España tras la dictadura del general Franco.

Pese a todo, el reequilibrio en sus relaciones bilaterales al hilo de la ho- mologación de España en un sentido europeísta y atlantista a tenor del proceso de transición y consolidación democrática e, incluso, la deriva atlantista y pro-norteamericana que caracterizó la política exterior de la era Aznar, no han modificado lo que William Chislett define como «el bajo perfil de España en Estados Unidos». Es sintomático, advierte el autor de España y Estados Unidos: en busca del redescubrimiento mutuo, que ningún español haya obtenido la mención de ciudadano honorario de los Estados Unidos, como Winston Churchill y Gilbert du Montier, marqués de Lafayette. Curiosamente a este último le fue concedida aquella mención por su lucha en la Revolución americana contra los británicos, un hecho reseñado en los manuales de historia escolares, mientras que el papel desempeñado por España y, en particular, por Bernardo de Gálvez -gobernador de Luisiana y cuyas acciones militares ocasionaron no pocos daños a la flota inglesa en el Caribe y el Golfo de México- tan solo ha dejado un eco de su nombre en una ciudad en Texas, Galveston (Chislett, W., 2005b).

La diferente temperatura que caracterizó el ambiente entre ambas cotas diplomáticas influyeron, que duda cabe, en el haz de imágenes que en un sentido y otro cruzaron el Atlántico. No obstante, el caudal de estereotipos 
atesorados a lo largo del tiempo entre españoles y norteamericanos devienen de procesos más prolongados y lentos que, ciertamente, son permeables a la agitación abrupta que el acontecimiento ocasiona en el curso vital de sus respectivas sociedades. Conviene aclarar que al utilizar el término estereotipo lo hacemos en el sentido en que lo define Emilio Lamo de Espinosa, como «un mapa cognitivo que simplifica la realidad poco conocida para hacerla manejable y comprensible», siendo por tanto «un producto de la economía del pensamiento y su semejanza inmediata» con los «mapas» que, al igual que los estereotipos, destacan y resaltan aquello que resulta relevante (Lamo de Espinosa, E., 1993: 13). En una misma dirección se encaminaría la delimitación del concepto que de ello hace Rafael Núñez Florencio, en cuya opinión, se trata de:

(...) clichés, de tópicos, simplificaciones, lugares comunes, imágenes triviales, generalizaciones, medias verdades o incluso falsedades que no se reconocen como tales (...) Son, por decirlo claramente, imágenes, símbolos, construcciones culturales que realizamos por pereza, por hábito, por aviesas intenciones, por necesidad de simplificar la realidad o para orientarnos en un mundo confuso y cambiante (Núñez Florencio R., 2001: 26).

La reflexión en torno a estas construcciones culturales recíprocas resultan determinantes no solo para la comprensión de la cultura política y su evolución a uno y otro lado del Atlántico sino también para la comprensión de la percepción del mundo y del lugar de sus respectivas sociedades en el mismo. Este complejo juego de imágenes y espejos, aderezado de múltiples paradojas que en ocasiones contrastan con el pulso de las relaciones diplomáticas, resultan cruciales para cualquier aproximación a la naturaleza de las relaciones entre españoles y norteamericanos en el curso del siglo XX.

Unas imágenes y estereotipos moldeados a fuego lento en el transcurrir del tiempo, pero matizados y corregidos en algunas ocasiones, distorsionados en otras, por el decurso de ambas comunidades nacionales en la sociedad internacional y por los propios lances que han determinado la evolución de su intrahistoria respectiva.

Estas consideraciones preliminares hacen, desde nuestra perspectiva, no solo aconsejable sino primordial detenernos en estas páginas iniciales en el análisis de las imágenes y estereotipos dominantes en las visiones recíprocas de españoles y norteamericanos a lo largo del último siglo. Todo ello como un componente fundamental para el estudio de las relaciones entre Estados Unidos y España. Un análisis que afrontaremos, en primera instancia, a tenor de una aproximación global al universo simbólico de sus visiones y percepciones recíprocas y, en segundo término, precisando el collage de esas imágenes en citas históricas de alto componente emocional en ambas o en una de estas sociedades -el "98", la guerra civil, los pactos secretos de 1953, 
José Luis Neila • Entre Cuba y las Azores...

el referéndum sobre la OTAN o la foto de las Azores-.

LAS MIRADAS DEL OTRO: EL UNIVERSO SIMBÓLICO DE NORTEAMERICANOS Y ESPAÑOLES

Las miradas e imágenes cruzadas entre españoles y norteamericanos a lo largo de los siglos XIX y XX han estado determinadas por una serie de mitos predominantes en las respectivas concepciones excepcionalistas de la historia y de su lugar en el mundo.

La excepcionalidad española, en palabras de Paul Isbell, "podría definirse como la creencia (que a veces roza el dogma) de que España no es, y nunca ha sido un país normal. La historia de España (...) ha fomentado el mito de que este país difícilmente sería capaz de integrarse de forma normalizada en la historia universal» y transformarse, en definitiva, en «un país moderno, democrático y próspero». Una convicción a tenor de la cual se fue fraguando una especie de «españolidad» que diferenciaba a España como nación y como cultura. Un complejo que sería utilizado con frecuencia «como justificación para una huida de la modernidad y para la adopción de medidas anormales y de excepción en la vida política española». Esta anomalía, que marcará a lo largo del siglo XX el debate sobre el problema de España, incidiría en la propia percepción de otros pueblos de España como una «suerte de 'barbarie' e incompetencia española en el campo político, un retraso económico permanente y una inferioridad crónica en general» (Isbell, P., 2001: 46-47).

La normalización de la sociedad española en el último cuarto del siglo XX ha favorecido la reinterpretación historiográfica de la excepcionalidad de España. Francisco Quintana destaca en la reciente historiografía española el «redescubrimiento de España como parte de una Europa plural». Es decir, "la tendencia a integrar los problemas hasta hace poco considerados específicamente españoles (recuérdese lo del Spain is different) en el marco de unas realidades que se van asentando de forma dispar (Quintana, 1998: 220-221). Lejos de ser un caso excepcional España, reflejaría los problemas de Europa ya antes incluso del siglo XX. Sus crisis y guerras civiles, afirman Sebastián Balfour y Paul Preston, no son sino formas específicas de las que asolaron al continente (Balfour, Preston, 2002: VII-VIII). Un giro historiográfico al que ya habían prestado su atención historiadores como Santos Juliá, Ludolfo Paramio, José Álvarez Junco o Juan Pablo Fusi a tenor de la reinterpretación del excepcionalismo y el fatalismo del devenir de España abogando por una lógica de la normalidad sin obviar la especificidad. En consecuencia, nuestra historia muestra razonables similitudes con Europa, incluso en su retraso. En última instancia, el fin del siglo XX para España -argumenta Emilio Lamo de Espinosa-clausura el mito casticista y sanciona la emergencia del nuevo mito europeísta. Supone la «emergencia y 
clausura de las dos España» (Lamo de Espinosa, 2001: 4).

Frente al mito de la anomalía de España, el excepcionalismo estadounidense se puede entender, en palabras de Paul Isbell, como «la fe, casi religiosa, de que los ciudadanos de esta nación fueron elegidos especialmente por el Ser Supremo para liderar, liberar y salvar al mundo». Un providencialismo que ha alimentado la impresión, incluso la certeza, de que "Dios les ha escogido a ellos para llevar la democracia a los pueblos del mundo, habiendo sido distinguidos por la mano del mismo Dios de entre los precedentes poderes mundiales precisamente por su fe democrática y por su emergencia como única superpotencia mundial que, supuestamente, no explota un imperio colonial» (Isbell, P., 2001: 48-49). A lo largo del siglo XX, el «Destino Manifiesto", bajo cuya consigna se legitimó la providencial misión de la conquista continental, se rescribiría al compás de los cambios de la política exterior norteamericana, primero al convertirse en una potencia mundial en el tránsito del siglo XIX al XX y, más adelante, al erigirse en una superpotencia tras el ciclo de guerras mundiales y al concebirse a sí misma como faro de la democracia en el mundo.

La presencia de ambos polos no dejaría de influir en el caudal de percepciones e imágenes recíprocas entre España y Estados Unidos, cuyos lienzos pincelarían el paisaje ideológico y cultural en los encuentros y desencuentros en el curso del siglo XX. Pero, ¿̇cuáles son los ingredientes básicos que conforman sus respectivos paisajes simbólicos en la antesala del siglo XX? Los estereotipos e imágenes que se fueron fraguando a lo largo del siglo XIX revelan la lejanía y el escaso conocimiento mutuo de españoles y norteamericanos. Es sintomático que en vísperas de la crisis del 98 la mayor parte de los españoles, afirma Rafael Sánchez Mantero, veían «en aquel país del norte de América a una nación joven e inexperta que nada tendría que hacer frente al peso, la tradición y la experiencia colonial de la vieja España» (Sánchez Mantero, R., 1998: 294). No obstante, la emergencia y la posterior hegemonía norteamericana modificaría radicalmente el conocimiento de los Estados Unidos durante la segunda mitad del siglo XX por parte de los españoles, aunque los prejuicios e imágenes vendrían determinadas por el curso de sus respectivas políticas exteriores y el propio devenir interno de sus sociedades.

\section{Estados Unidos en el lienzo español}

El antiamericanismo que afloraría en los medios de opinión españoles en el contexto del 98, al que luego nos referiremos, arraigaría en una serie de prejuicios que se habían ido hilvanando a tenor de ciertos conceptos emblemáticos como el protestantismo y el igualitarismo de la sociedad norteamericana, así como de la creciente amenaza que supondría sus aspiraciones sobre Cuba 
para la integridad de las posesiones ultramarinas españolas.

La encarnación de la democracia en el desarrollo histórico de los Estados Unidos, como argumenta Antonio Niño en un excelente estudio al que haremos reiteradas alusiones, fue percibido en el siglo XIX como una amenaza por ciertos sectores de la sociedad española. En este sentido, para la Iglesia católica y los sectores tradicionalistas los Estados Unidos «encarnaban todos los males de la democracia y el protestantismo juntos», cristalizando una imagen de país incivilizado, materialista y sin principios. A comienzos del siglo XX cristalizaba la imagen de los Estados Unidos como escaparate del futuro, como un país identificado con la "continua modernización y el dinamismo social». De modo que al peligro democrático, la modernización económica y social inoculaba el temor entre los sectores más conservadores del viejo continente al percibir una amenaza al orden social tradicional. A la emergencia de la sociedad igualitaria y de masas, estos sectores tenderían a polarizar sobre los Estados Unidos la imagen de una sociedad vulgar, ordinaria y de escaso refinamiento, «un páramo cultural e intelectual dirigido por nuevos ricos burdos y sin estilo, incapaces de alcanzar una 'espiritualidad elevada'».

En cambio, para una minoría ilustrada e informada de españoles el modelo político y jurídico norteamericano presentaba un gran atractivo. Entre los círculos críticos hacia el integrismo católico y el poder oligárquico, entre ellos algunos de los más destacados líderes del republicanismo federal -caso de Pi y Margall- o intelectuales como Rafael María Labra, tejerían una imagen positiva del modelo sociopolítico estadounidense (Niño, 2005: 58-59).

El antiamericanismo que eclosionaría en la crisis de fin de siglo devendría, asimismo, de la amenaza que la política norteamericana suponía para los intereses españoles en el continente americano, tal como lo fue con anterioridad Inglaterra. En este sentido la retórica anticolonialista y las tendencias expansivas que habían puesto de manifiesto los Estados Unidos a lo largo del siglo, cuyos fundamentos doctrinales se habían acrisolado al calor de la «Doctrina Monroe» y el «Destino Manifiesto», habían sido un tema de recurrente preocupación para la política española en el ochocientos.

Tras la crisis del 98 al antiamericanismo latente de los sectores más conservadores a tenor del giro imperialista de la política exterior de los Estados Unidos y la extraversión de su capitalismo en América y Asia, el panamericanismo, como versión de su proyecto hegemónico hemisférico, sería percibido como una «amenaza para la comunidad cultural iberoamericana y para las propias expectativas hispanoamericanistas españolas». A partir de la década de 1920 el radicalismo de izquierdas, en cuyo seno había cristalizado una imagen modélica de los Estados Unidos como paradigma de modernización, comenzaría a mostrar un discurso crítico hacia la política im- 
perialista norteamericana en América Latina, como se desprendería de la obra de Luis Araquistáin. Un componente en el discurso antiamericano que erosionaría la imagen que Estados Unidos como paladín de la democracia había labrado entre la izquierda española (Niño, 2005: 60).

El antiamericanismo, como puntualiza Paul Isbell, adquiriría diferentes expresiones según las diferentes tesituras de la vida política española:

(...) España alimentó un antiamericanismo latente, un sentimiento reaccionario que no se suavizaría con el paso del siglo XX. Luego, la negativa de los EE.UU. a comprometerse como aliada con la democracia de la Segunda República durante la Guerra Civil, y la indiferencia hacia los principios liberales que parecía mostrar EEUU al dejar en el poder el régimen fascista después de la guerra mundial, garantizaría el anti-americanismo (sic) de la izquierda española; mientras la humillación sufrida por la derecha al tener que aceptar la ayuda y la presencia militar norteamericana durante la guerra fría, simplemente para asegurar la estabilidad y prolongación del régimen franquista, tuvo como consecuencia que el antiamericanismo tampoco se desvaneciera fácilmente en la España conservadora (Isbell, P., 2001: 51).

Desde esa perspectiva el antiamericanismo español participaría de los componentes del antiamericanismo que se irá fraguando en el continente europeo desde el siglo XIX, pero que comenzará a socializarse y difundirse tras el ciclo de guerras mundiales. Este sentimiento, en opinión de Alessandro Seregni, vendría motivado por un doble impulso: en primer lugar, en la medida en que la «modernización americana ante los ojos de algunos europeos se convierte en una amenaza para la integridad cultural, religiosa y nacional y una fuente de corrupción moral para la juventud», además de representar un choque entre una cultura aristocrática, en decadencia, y una cultura de masas, en plena emergencia; y en segundo lugar, como consecuencia de «sentimientos de frustración, de decepción y de rabia que los países europeos sienten por la incesante ascensión y por el crecimiento extraordinario de Estados Unidos» (Seregni, 2007: 35-37).

\section{España en el lienzo norteamericano}

A finales del siglo XIX en Estados Unidos se tenía muy escasa información sobre España. La prensa, cuando daba cuenta de algún aspecto de la política, de la historia o de la cultura españolas reproducía básicamente fragmentos y anécdotas recogidos en los libros de viajes, obras divulgativas y manuales escolares elaborados por los historiadores en el siglo XIX. Tras la guerra hispano-norteamericana, para la mayor parte de los ciudadanos norteamericanos -escribe Rafael Sánchez ManteroEspaña seguía siendo:

(...) ese país exótico, oscuro e intransigente que había dado lugar a 
José Luis Neila • Entre Cuba y las Azores...

la Inquisición, a las atrocidades de la conquista y a la intolerancia de la iglesia católica. Los jóvenes de aquel país habían sido educados bajo una enseñanza que criticaba sistemáticamente la empresa que España había emprendido en el nuevo continente a partir de 1492. Su pasado y la interpretación de ese pasado que habían hecho los historiadores norteamericanos que habían redactado esos manuales habían condicionado fuertemente la idea de España entre los que habían aprendido la historia con la lectura de sus páginas (Sánchez Mantero, R., 1998: 299).

La recurrencia en torno a ciertos extremos como el fanatismo religioso, encarnado en la institución de la Inquisición, en las atrocidades y el expolio de la conquista de América, o en síntomas más contemporáneos como la anarquía política o el atraso general del país, engarzan con una de las fuentes principales en la configuración de la imagen de España, los prejuicios anti-españoles tradicionales de la cultura británica. Unas relaciones marcadas por la gravidez de las rivalidades religiosas y políticas entre la Inglaterra protestante y la España católica desde los siglos XVI y XVII y que cristalizarían en la «leyenda negra» de la católica e imperial España. Fundamento de la interpretaciones que sobre España aparecían en manuales de historia, su labor -como bien subraya Antonio Niño- prolongaría "con más detalles la tendencia de los españoles a la opresión de otros pueblos, a las persecuciones religiosas y las rapiñas coloniales» (Niño, 2005: 64).

Esta aproximación negativa a España se extendería, asimismo, hacia todo lo hispano. De hecho, en el curso de los siglos XIX y XX la imagen estadounidense de lo hispano se articularía con elementos predominantemente hispanoamericanos. La imagen de España tendería a confundirse con la de América Latina y los estereotipos se trasladarían «de un lado a otro en un vaivén de influencias mutuas» (Lamo de Espinosa, 1993: 18).

El primer hispanismo norteamericano que se conformó desde el segundo cuarto del siglo XIX contribuiría de forma muy notable a la construcción de la imagen romántica de España como un país exótico y atractivo por el legado de su alta cultura. En esta tradición se enmarcarían la obra de George Erving, encargado de negocios en Madrid durante la década de 1820 , que publicaría el primer libro en inglés sobre el idioma y la cultura vascos, y sobre todo la obra de Washington Irving, autor de uno de los libros más divulgados y duraderos en la forja de la imagen romántica de España Tales from Alambra (Cuentos de la Alambra) publicada en 1831, así como la de su coetáneo Alexander Slidell Mackenzie. En este tratamiento romántico, España -en opinión de Rafael Núñez Florencio- ofrecía lo que «le faltaba a un país que gozaba de opulencia material, pero que se sentía huérfano y desamparado en ciertos aspectos de la mitología nacional: un pasado grandioso, empresas caballerescas, glorias perdurables, hazañas deslumbrantes, todo eso era lo que podía encontrarse en la península ibérica» (Núñez Florencio, 2001: 233). 
A estas aportaciones habría que añadir la aparición de las primeras obras de un hispanismo erudito encarnado en la extensa History of Spanish Literature de George Ticknor, publicada en 1849, o del poeta Henri Wadsworth Longfellow. En el ámbito de la historiografía aquel primer hispanismo historiográfico cristalizaría en los libros del historiador romántico William Hickling Prescott, quien nunca llegaría a visitar España, y cuya interpretación de la historia de España estaba directamente inspirada en la «leyenda negra». Prescott venía a representar en la historiografía lo que Irving significaba en la narración, o Longfellow en la poesía.

La imagen negativa y acusatoria que aparecía reflejada en la prensa, los libros de viajes y los libros de textos estaba revestida, a su vez, de un afán moralizador en la medida en que se proponía a España como contramodelo, es decir, como ejemplo de la actitud que no debía seguirse si se quería actuar honestamente y preservar una recta conducta. En palabras de Rafael Núñez Florencio:

(...) en el mejor de los casos, subyace a ese intento de comprensión o interpretación históricas una actitud en cierto modo paternalista, en un doble sentido: los estadounidenses, que disfrutan desde hace tiempo de una amplia libertad política y una no menos asentada estabilidad, miran con simpatía la lucha de un pueblo por su libertad, contra la opresión política y religiosa, etc.; por otro lado, como consecuencia de esa misma actitud, piensan que pueden contribuir en alguna medida con sus consejos a sacar al país de su postración, de su ocaso centenario (Núñez Florencio, R., 2001: 244).

Estas percepciones y contrastes quedarían explicitados en torno a lo que Richard Kagan ha definido como el "paradigma Prescott», base de la imagen de España en Estados Unidos durante un largo tiempo, de acuerdo con el cual España aparecía como contramodelo y como antítesis a los valores y la posición de la República norteamericana. "América fue el futuro -republicana, emprendedora, racional; mientras España -monárquica, indolente, fanática- representó el pasado» (Payne, 2003: 156). En definitiva, Estados Unidos encarnaba los valores y principios de la Modernidad Occidental, mientras que España ofrecía la imagen decadente de la huida de la Modernidad.

Estos estereotipos, fraguados muchos de ellos en los siglos XVI y XVII acabarían por ser asimilados y canalizados hasta convertirse en tradición oficial de las culturas nacionales, no solo de los Estados Unidos sino también de los Estados europeos a lo largo del siglo XIX. Así, como bien afirma Enric Ucelay-Da Cal, la imagen de España que predominó en la cultura europea desde principios del siglo XX era la de la consideración de nuestro país como «un ejemplo de decadencia», como "su ejemplo histórico por excelencia». Una idea que en el entorno cultural de finales de la centuria anterior, influido por el darwinismo político, se asociaba a la degeneración racial (Ucelay-Da Cal, 
José Luis Neila • Entre Cuba y las Azores...

E., 1992: 26-30). En el caso español, a diferencia de los ámbitos culturales francés e italiano, no se generó una amplia literatura de respuesta negando esos supuestos racistas, salvo alguna excepción en el entorno del 98, como Rafael Altamira. El noventayochismo, como enfatiza el citado autor, dada la dimensión del Desastre partió del «hecho» de la decadencia, "asumiéndolo para formular esquemas pesimistas y anti-industriales. Solo con la generación del 14 se afrontó una salida en clave europeizadora. Vista desde fuera, la perspectiva de la reforma civil presentaba una doble sensibilidad: de un lado, existía la convicción de «que las complejas instituciones representativas y/o participativas anglosajonas o nórdicas, como la democracia o el parlamento, eran demasiado delicadas para mediomestizos soñolientos y vagos, capaces de cualquier estropicio por estar a merced de su sangre caliente»; y de otro, el «afán misionero de culturas todavía entonces militantemente protestantes, alberga la esperanza de la conversión, que los degenerados se regeneraran» (Ucelay-Da Cal, 1992: 39).

Aquellas imágenes y estereotipos serían objeto, por parte de ambos contendientes, de una intensa manipulación propagandística durante la guerra hispano-norteamericana. La imagen de España en los Estados Unidos, pese a la lejanía y el bajo perfil de sus relaciones político-diplomáticas bilaterales durante el primer tercio de siglo, tendería a mejorar al socaire de una mayor, aunque moderada, interpenetración económica y cultural. En este sentido, la presencia y la influencia norteamericanas en España, e incluso el propio fenómeno de la americanización ${ }^{1}$ que eclosionará tras

1 En torno al uso del concepto «americanización", conviene utilizarlo con prudencia y rigor histórico. Alessandro Seregni advierte sobre el origen del propio término como un producto específico de Estados Unidos y de su cultura. Sería, pues, una «palabra que se refiere a un grupo de valores, prácticas e instituciones característicos de Norteamérica, estimados por ser representativos y constitutivos de la identidad nacional». Sin embargo, desde la perspectiva y la experiencia europeas el término remite a otros significados, entre los cuales el más significativo en nuestro caso apuntaría a la superposición del concepto con la penetración del american way of life, es decir, el sistema de vida americano. Una apreciación que asociaría la noción de americanización con la de modernización, aunque esta última sea más amplia (Seregni, A., 2007: 18-22). En un plano más amplio, argumenta Samuel Huntington, la modernización «no significa necesariamente occidentalización». Las «sociedades no occidentales se pueden modernizar y se han modernizado de hecho sin abandonar sus propias culturas y sin adoptar indiscriminadamente valores, instituciones y prácticas occidentales» (Huntington, S., 2005: 100). No obstante, la emergencia del «siglo americano" y la hegemonía estadounidense tras el ciclo de guerras mundiales conduciría a un nuevo diseño del «sistema-mundo moderno/colonial», en la terminología de Walter D. Mignolo. «La misión civilizadora en su versión europea -en palabras del citado autor- se rehizo en torno a los Estados Unidos cuando protagonizó su ascenso a potencia mundial, rearticulándose con el Destino Manifiesto. Tras la Segunda Guerra Mundial fueron el desarrollo y la modernización los que tomaron el relevo, relegando la misión civilizadora a un lugar 
la II Guerra Mundial, es indisociable de la creciente presencia de los Estados Unidos en el continente europeo a medida que avance el siglo. La tesitura de la Guerra Civil suscitará reacciones de diverso signo en la sociedad norteamericana, especialmente en ciertos círculos periodísticos y políticos, que mostrará en términos generales sus simpatías hacia la República pero que, en modo alguno, alterarían la política de no intervención en los asuntos españoles.

La imagen de la dictadura de Franco en los círculos políticos, militares y periodísticos norteamericanos, impregnada en términos generales de los recelos que alimentaba la persistencia de un Estado autoritario residuo de la era de los fascismos, se moduló según diferentes claves, tanto en tiempos de la guerra mundial como en la posguerra y la guerra fría. En consecuencia, los objetivos de guerra norteamericanos, en esencia la neutralización de la península ibérica, y más adelante la instrumentalización de la posición geoestratégica de España en el ajedrez de la guerra fría, favorecido también por los signos católicos y anticomunistas emitidos por el régimen de Franco, impulsarían la asociación asimétrica que entre Estados Unidos y España se entablaría en 1953. En este sentido, como bien argumenta el año de inflexión en las relaciones hispano-norteamericanas sería 1947. El paulatino redireccionamiento de la política norteamericana se orientaría

secundario» (Mignolo, W.D., 2003: 358). en un doble sentido, "de nuevos lazos diplomáticos, militares y económicos, al mismo tiempo que se alentaba la reforma del sistema político». A partir de 1953, la imagen de España se «suavizó», a la vez que se irían intensificando paulatinamente los contactos económicos y científicos. Sería a partir de los años cincuenta y sesenta cuando tendría lugar la eclosión del hispanismo historiográfico, en especial por su historia contemporánea, por aquel entonces «el gran país 'excepcional' de Occidente» (Payne, 2003: 162-164). En última instancia, habría que esperar a la transición y consolidación de la democracia en España, la normalización y homologación de la posición de España en su eje de referencia atlántico y europeo y con los propios Estados Unidos, muy prudentes y reticentes en los inicios de la transición, y la modernización de la sociedad española para la introducción de nuevas claves «normalizadoras» en la imagen de España en Estados Unidos.

IMÁGENES EN EL ESPEJO

ATLÁNTICO Y CUMBRES

EMOCIONALES EN LAS

RELACIONES HISPANO-

NORTEAMERICANAS EN EL CURSO DEL SIGLO XX

Profundicemos en este recorrido, deteniendo nuestra atención en ciertas cotas cronológicas de alto valor simbólico e histórico en las relaciones entre españoles y norteamericanos, para 
valorar aunque sea de forma somera el cosmos de imágenes preeminente en una u otra dirección según las diferentes tesituras temporales.

La crisis de fin de siglo, corporeizada en la guerra hispano-norteamericana de 1898, agitaría de forma convulsa no solo el horizonte político-diplomático y militar en que se habían desenvuelto hasta ese momento sus relaciones bilaterales sino también el universo de imágenes y estereotipos que habían alimentado sus proyecciones recíprocas. La negativa noción de los españoles transmitidas desde la literatura, la prensa y el sistema educativo facilitó el apoyo a los designios del «Destino Manifiesto" sobre las posesiones que aún permanecían en manos de España en el nuevo mundo. Desde esta lógica, cuando estalló la guerra de Cuba la denuncia de las atrocidades cometidas por los españoles sobre la población cubana y en sus otras posesiones para justificar la intervención en defensa de la libertad y esgrimiendo motivos humanitarios, no resultó difícil de asociar con la «leyenda negra» y los abusos cometidos por los colonizadores españoles. Se articulaba de este modo un discurso y una propaganda en que cristalizaba una rápida asociación entre Hernán Cortés y la expeditiva política del general Weyler en Cuba. El historiador y diplomático norteamericano Carlton J. Hayes subrayaba en su obra The United States and Spain, publicada en 1951, cómo la guerra de 1898 había revitalizado los estereotipos históricos y las visiones latentes que sobre España se habían conformado en el mundo anglosajón.

El desconocimiento de muchos norteamericanos acerca de la auténtica situación de España en el fin de siglo y su potencial bélico, como bien apunta Rafael Sánchez Mantero, era hasta tal punto extrema que cuando la flota española del almirante Cervera zarpó con destino a la isla de Cuba, a algunos norteamericanos «les asaltó el temor de que estos barcos pudiesen dirigirse a la costa de su país. Tan inseguros se encontraban que hubo quien sacó su dinero de los bancos de las ciudades costeras para depositarlos en otros del interior» (Mantero Sánchez, 1998: 304-305).

La caricatura del viejo torero evocada en la prensa, como metáfora de la decadente España, encajaba a su vez con el discurso del darwinismo político, tan en boga en el curso de entre siglos, de modo que el conflicto se teñía de la dialéctica de la lucha entre las razas, como motor de la historia. Desde esta panorámica, la decadencia de España y su deserción de la modernidad contrastaría con la misión providencial de Estados Unidos como adalid de la modernidad y promotor y defensor del modelo liberal político y económico. En este sentido, no nos resistimos a reproducir las opiniones de algunos personajes notables de la vida política norteamericana, como la del representante norteamericano en Madrid, Stewart L. Woodford, quien en 1895 argumentaba que España no podía introducir reformas en Cuba 
porque el pueblo español no entendía los conceptos de libertad y autogobierno a la manera de los anglosajones (véase Pardo, 2003: 17); o como la de Henry Cabot Lodge, quien llegaría a calificar a España de «medieval, cruel y moribunda» (véase Sanchez Mantero, 1998: 303).

En España, la efervescencia patriótica motivada por la crisis del 98 sembraría imágenes antiamericanas en los medios de opinión. Estados Unidos, como puntualiza Rosa Pardo, dejaba de ser considerada como una nación joven y dinámica para convertirse en «otra de mercaderes, aventureros y mercenarios codiciosos, racistas, caricaturizados como cerdos, bandidos, bárbaros y borrachos 'tocineros jingoes'». La intervención de los Estados Unidos se calificó como propia de un país incivilizado, sin prejuicios y materialista (Pardo, R., 2003: 18). Su justificación humanitarista no podía ocultar su eminente carácter imperialista contrario a los preceptos del derecho internacional. Unos perfiles sobre los que se proyectarían los recelos tradicionales de la Iglesia católica y los sectores más conservadores y tradicionalistas de la sociedad española de fin de siglo.

Tras la guerra hispano-norteamericana de 1898, el redireccionamiento paulatino de las relaciones bilaterales tendería a influir sobre las imágenes recíprocas. Si bien es cierto que en el caso norteamericano esta evolución de la imagen de España no se apreció de forma inmediata en los manuales escolares, comenzará a percibirse en la prensa, medio desde el cual se observaría un aumento considerable del número de noticias y de informaciones sobre España y los españoles. La "política española, la familia real, la cultura e incluso las costumbres de nuestro país -escribe Rafael Sánchez Manterocomenzaron a suscitar la curiosidad y hasta, en algunos casos, la simpatía y admiración de los columnistas de diarios como el The New York Times» (Sánchez Mantero, 1998: 307).

La Guerra Civil española (19361939), en esta sucesión de hitos cronológicos de alto valor simbólico en el terreno de las imágenes recíprocas, no aportaría novedades significativas, en opinión de Rafael Núñez Florencio, en el imaginario en torno a España o el «modo de concebir lo hispano». Ciertamente, lo que sucedió fue que el cúmulo de imágenes, símbolos, consignas, estampas y eslóganes utilizados por la propaganda de uno y otro bando se establecieron a "partir de coordenadas ideológicas y sentimentales que estaban vigentes desde un siglo antes: para entendernos, y simplificar, sobre el telón de fondo de la España romántica» (Núñez Florencio, R., 2001: 273). No obstante, la guerra civil, una de las grandes vetas historiográficas de la historia contemporánea de España, ocuparía un lugar central en el hispanismo anglosajón, hasta el punto de determinar en buena medida la interpretación del siglo XX español.

En lo concerniente a la actitud de la opinión pública norteamericana respecto de la guerra civil española, 
se suele considerar -afirma Stanley G. Payne- que esta apoyó -al menos sentimentalmente- al bando republicano. Pero lo cierto es que esta opinión concerniría a reducidos sectores de la sociedad norteamericana, puesto que la «mayoría de la población no tenía opinión alguna, ni en pro ni en contra de nadie. Hay que recordar que una parte de la población estadounidense todavía cree, en pleno siglo XXI, que España está en «algún rincón de Sudamérica». Entre esa minoría ilustrada, los sondeos mostraban que durante la contienda civil las simpatías se decantaban en pro de los republicanos, aunque incluso en estos sectores los deseos de intervenir eran muy escasos. La República, en definitiva, atraería las simpatías de los círculos progresistas y de ciertos sectores conservadores (Payne, 2003: 157). De otro lado, la imagen del bando insurgente era más negativa, y tendería a asociarse con los fascismos a medida que la política exterior norteamericana se hizo menos permisiva hacia el fascismo y crítica respecto de la práctica del apaciguamiento.

Así, frente a la propaganda y la interpretación del conflicto promovida desde el bando insurgente en torno a la contrarrevolución preventiva y la reacción contra el Frente Popular, su autoafirmación como la nación misma y el conjunto genuino del país y la canalización de la tradición católica en términos de Cruzada, algunas de las interpretaciones de las explicaciones sociales de la guerra articuladas con el bando republicano influirían, en opinión de Enric Ucelay Da Cal, en la historiografía anglosajona. De este modo, la línea explicativa del Frente Popular como "plataforma amplia» en 1936, asumida por el propio Estado republicano, abundaba en la convicción de que en 1936 la sociedad española era esencialmente feudal, cargando «con el peso muerto de una Iglesia retrógada y de un Ejército al servicio de los grandes terratenientes, los cuales formaban el núcleo decisivo de la oligarquía histórica». Estas «fuerzas atávicas» eran las que se habían alzado contra el gobierno legítimo al introducir «tímidas reformas democráticas». Esta interpretación se filtraría, no sin matices, en investigaciones tan acreditadas como la historia de la República y la Guerra Civil del historiador norteamericano Gabriel Jackson, en 1965.

El respaldo mayoritario a la política de neutralidad y de no intervención, en el caso de la guerra civil española, auspiciada por la Administración de F.D. Roosevelt, era muy sensible a la desilusión que la gran mayoría de la población norteamericana compartía en relación con las guerras europeas y la participación en la Guerra del Catorce, que en no pocos casos interpretaban como resultado de la manipulación propagandística británica (Payne, S.G., 2003: 157).

Tras el triunfo de la coalición conservadora y reaccionaria en España, la consolidación internacional del régimen del general Franco devendría en uno de los hitos fundamentales de su política exterior, la firma de los Pactos 
secretos hispano-norteamericanos el 26 de septiembre de 1953. La alianza establecida con Estados Unidos dejaba atrás una política exterior que con mayor o menor rigor se había atenido secularmente a la neutralidad, pero que con Franco ya en el poder quedaría cuestionada a tenor de su zigzagueo entre la neutralidad y la no beligerancia hacia el Eje durante la Segunda Guerra Mundial. El aislamiento internacional a que se vería sometido el régimen, como residuo de fascismos del período de entreguerras, en la segunda posguerra mundial quedaría solemnemente sancionado en la Resolución 39 (I) de la Asamblea General de las Naciones Unidas, de 12 de diciembre de 1946, por la que se excluía al Gobierno del general Franco de participar en los organismos internacionales establecidos por la organización. El desleimiento del aislamiento internacional de España se agitaría al albur de la fractura en el seno de la coalición vencedora y la escenificación de la dinámica de bloques de la Guerra Fría. El orden internacional de la bipolaridad brindó a Franco la oportunidad de sortear desde finales de la década de los cuarenta los rigores de su marginación internacional y lograr un acomodo internacional fundamentado en su discurso anticomunista y católico, baluarte de sus dos grandes activos del año 1953, la firma del Concordato con la Santa Sede además de los mencionados Pactos con Estados Unidos.

Las relaciones político-diplomáticas entre Estados Unidos y España habían descrito un bajo perfil desde principios de siglo y desde los años cincuenta comenzarían a asumir un lugar privilegiado, al menos desde la parte española, al calor de su hegemonía internacional.

El contenido de las relaciones político-diplomáticas entre ambos Estados, marcadas por su naturaleza asimétrica, modulada y matizada según diferentes momentos históricos, se tejería esencialmente sobre la potencialidad geoestratégica de España. La clave sobre la que precisamente se había producido el redireccionamiento de la política exterior española tras la crisis del 98 al incardinarse en el haz de intereses de las potencias europeas -Francia y Gran Bretaña, en particular-. Este factor sería determinante, como bien ha estudiado José Antonio Montero, en las relaciones entre España y los Estados Unidos durante la Guerra del Catorce, especialmente tras el abandono de la neutralidad norteamericana y su implicación como asociada al conflicto (Montero, 2004; y véase, asimismo, Neila, 2007: 150158). Durante los años de la Segunda Guerra Mundial la posición de España en el mapa nuevamente volvería a jugar un papel esencial en la política de las potencias anglosajonas para neutralizar el espacio ibérico, aunque la política de Washington, a diferencia de los deseos de Londres, se atuvo a una actitud más aséptica y lejana respecto del rumbo de los asuntos internos de España -como se desprende de las memorias del embajador norteamericano en España, Carlton J.H. Hayes- (Hayes, 1946). Una actitud que se prolongaría en la 
inmediata posguerra mundial para desánimo de los españoles en el exilio y que se enfatizaría a medida que el fracaso de la paz dejase paso a la Guerra Fría y el temor a que una alteración de la situación interior pudiera favorecer el establecimiento de un régimen comunista en España. La escasa simpatía que despertaba la España de Franco en la opinión pública norteamericana y la marginalidad de España respecto de la vida internacional -recordemos su omisión del Plan Marshall como magníficamente satirizaría Luis García Berlanga en la película Bienvenido $M r$. Marshall-era plenamente compartida por el presidente Harry Truman. En una comparecencia en una rueda de prensa en febrero de1952 declaró «nunca me ha gustado mucho España». A Truman, bautista muy devoto, nunca le gustó el régimen antidemocrático del general Franco y le preocupaban los efectos de la falta de libertad religiosa en España sobre la comunidad protestante (véase Seregni, 2007: 176).

Pero el desarrollo del tablero de la Guerra Fría acabaría por decantar el giro realista de la política exterior norteamericana y la preeminencia de los puntos de vista defendidos por el Pentágono, que ya había contemplado la conveniencia de establecer bases militares en España dada su posición geoestratégica en el sur de Europa. En diciembre de 1947, el Consejo de Seguridad Nacional emitió un informe sobre España -conocido como el documento NSC 3-, que acabaría siendo aceptado por el presidente Truman y se conver- tiría en la política oficial desde 1948 , en el cual se invitaba a «abandonar los prejuicios sobre nuestros intereses en España y reorientar nuestra política en consecuencia» (véase Chislett, 2005 a). Se iniciaba, en consecuencia, un camino que abriría al acceso de la España de Franco a los créditos norteamericanos, el restablecimiento de la normalidad diplomática con el envío del embajador norteamericano Stanton Griffiths en 1950 y, obviamente, el proceso negociador que culminaría en los Pactos de 1953. Estados Unidos, como bien afirma Alessandro Seregni, no quería influir en la política interna sino tan solo disfrutar de las ventajas estratégicas de su nueva posición en España, como una pieza más en el ajedrez de la Guerra Fría (Seregni, 2007: 178).

El Acuerdo sancionaba la vinculación asimétrica de España al sistema de seguridad occidental, a tenor de un instrumento menor -un executive agreement- que no requería la ratificación del Senado, y la concesión de importantes parcelas de soberanía como precio a la supervivencia y la aceptación internacional del régimen de Franco. Para Franco, afirma William Chislett, el acuerdo fue un triunfo en la medida en que le eximía de una "liberación política», a la vez que ganó "respetabilidad internacional» (Chislett, 2005 a), aunque no cubría aspectos sustanciales de la seguridad de España como la frontera sur e introducía a España plenamente en los riesgos de la Guerra Fría, entre ellos la amenaza nuclear, como se pondría de relieve en el acci- 
dente de Palomares en 1966, cuando un B-52 perdió sus cuatro bombas de hidrógeno al colisionar con un avión cisterna.

La aproximación de la diplomacia española, a tenor de los esfuerzos del ministro de Asuntos Exteriores Alberto Martín Artajo y la misión encomendada a José Félix de Lequerica, como inspector de embajadas en Estados Unidos para la articulación del Spanish lobby (véase Elordi, 2003: 19), y la posterior firma del acuerdo hispanonorteamericano de 1953 acabarían por silenciar las actitudes y las críticas antiamericanas que de forma habitual habían aflorado en la prensa y la publicística, como consecuencia de la censura y de la propaganda pro-americana del régimen. El pro-americanismo tenía por misión, afirma Alessandro Seregni, forjar una imagen de los norteamericanos como «nuevos aliados, familiares y simpáticos», especialmente en aquellas regiones en donde se habrían de establecer las bases militares. Pero ese largo silencio no «equivalía ni a la muerte del antiamericanismo, ni tampoco a su transformación en una actitud de respeto o amistad hacia Estados Unidos». De hecho, «todo quedaba en la sombra, aparentemente dormido». Las consignas en las que se arremetía contra Estados Unidos, asociándolo a la masonería, la democracia, el liberalismo, el imperialismo, la plutocracia o la estandarización y la maquinización de la sociedad, que habían sido punto de encuentro de la prensa del régimen e incluso de algunos de los artículos publicados por Franco en Arriba entre 1946 y 1952, quedaban larvadas y escondidas «bajo la superficie» (Seregni, 2007: 182).

Desde la firma de los Pactos secretos hispano-norteamericanos en 1953, la percepción del pasado, desde un plano retrospectivo, ha sido -en opinión de Antonio Niño- objeto de interpretación al menos desde dos ópticas: desde el prisma de los atlantistas y desde la panorámica de los europeístas. Desde la primera óptica de aproximación, los atlantistas, la conclusión de aquellos pactos no debe interpretarse tanto como un salvavidas «al que se agarró la dictadura franquista para prolongar su existencia» sino como «una opción estratégica apoyada en razones más profundas (...) y acertada a largo plazo, dada la evolución que ha seguido posteriormente el sistema internacional». Franco, no de forma consciente, habría introducido «en el país el caballo de Troya a través del desarrollo y la modernización», creando las «condiciones que acabaron minando su régimen autoritario» y facilitando «su sustitución por una democracia moderna». Una interpretación que contaba con numerosos precedentes en la historiografía norteamericana, caso de las tesis de Ernest O. Hauser, Rubottom y Carter Murphy. Los defensores de los pactos habrían usado, en términos generales, este argumento para justificar y legitimar la cooperación de Estados Unidos con la dictadura del general Franco. En este sentido, la "presencia estadounidense contribuyó a abrir resquicios en la aislada sociedad española por los que empe- 
zarían a entrar los principios inherentes a las sociedades modernas, necesarios en todo caso para que después de 1975 prosperasen las reformas políticas». El argumento enraizaría así con la tradición del «Destino Manifiesto», de modo que la sutil intervención de Estados Unidos en España a lo largo de tres décadas habría sido la responsable de crear las condiciones idóneas para que el pueblo español pudiera, más adelante, alcanzar aquello de lo que se veía privado "por su atraso secular». Se habría favorecido, de este modo, actitudes evolucionistas, no de forma intencionada en esta ocasión, hacia formas más tolerantes, liberales y democráticas.

De otro lado, la perspectiva argumentada por los europeístas no canaliza la reflexión desde los efectos del proceso histórico sino desde la panorámica de los «propósitos, intenciones y acciones efectivamente emprendidas por los actores». Se suscitaba, en consecuencia, la responsabilidad si la hubiera habido de «la política exterior estadounidense en la subsistencia del régimen franquista». Las sucesivas administraciones estadounidenses habrían estado fundamentalmente interesadas en lograr sus objetivos centrales, la utilización de las instalaciones militares conjuntas e «incorporar a España al sistema defensivo occidental». Está fuera de toda duda que la democratización del régimen, «de haberse producido de forma espontánea, habría tenido algunas ventajas para los intereses estadounidenses, hubiera favorecido la cohesión ideológica del bando occidental y se habría podido levantar el veto al ingreso de España en la OTAN». Sin embargo, «nunca se tomó una decisión para potenciar activamente la evolución democrática de España, porque ello hubiera puesto en peligro el objetivo supremo de garantizar la colaboración del régimen para el buen uso de las bases». El interés estratégico por garantizar el uso de las bases militares habría marginado el interés por una liberalización del régimen franquista en pro de una mayor coherencia y cohesión ideológica de Europa Occidental. De hecho, cuando se inició el proceso de transición, la actitud de las instituciones norteamericanas fue menos activa y resuelta que las actuaciones de los gobiernos europeos occidentales. A la hora de hacer balance de las estrategias para la promoción de la transición a la democracia desde los actores internacionales en liza, el citado autor concluye afirmando que:

Los europeístas señalan, a este respecto, que la cooperación económica y la promoción de los intercambios de todo tipo, como los que realizó la Europa democrática con la España franquista en su última etapa, no fue incompatible con un aislamiento político y estratégico muy diferente a la alianza y al apoyo que simultáneamente proporcionaba a la dictadura los Gobiernos de los Estados Unidos. Se trata de la diferencia de actitud de la Europa del Mercado Común, que toleró el régimen franquista al tiempo que fomentaba los intercambios con la sociedad española, y la actitud de Washington, que se alió abiertamente con el dictador y cooperó militarmente con él (Niño, 2003: 21-24). 
Este bagaje histórico y este caudal de experiencias, imágenes y percepciones que han alimentado el antiamericanismo tanto de «derechas» como de »izquierdas» determinarían, conjuntamente con la propia actitud y los gestos de las administraciones norteamericanas, los juicios y los prejuicios hacia Estados Unidos en los medios políticos y de opinión españoles durante el proceso de transición y consolidación de la democracia.

De acuerdo con estos precedentes y a tenor de la convulsa situación en el flanco mediterráneo del sistema de seguridad occidental, la salida de la presencia norteamericana en Libia en 1970 y la preocupación manifiesta por la «Revolución de los Claveles» en Portugal en 1974 enfatizaron la prioridad geopolítica del espacio ibérico desde la óptica norteamericana. El embajador norteamericano en España desde 1975 hasta 1978, Wells Stabler, confesaba que Estados Unidos «no hizo en realidad gran cosa» por promover algún tipo de cambio político en la España postfranquista. Su preocupación giró fundamentalmente en torno a la estabilidad de sus prioridades geoestratégicas. De hecho, el 24 de enero de 1976 cristalizaba el nuevo Tratado hispano-estadounidense de amistad y cooperación -no un simple acuerdo como había transcendido hasta ese momento-, enteramente negociado antes de la muerte del general Franco pero firmado por el ministro de Asuntos Exteriores, José María de Areilza, miembro del primer Gobierno de la
Transición presidido por Arias $\mathrm{Na}$ varro. Es sintomático, asimismo, que a diferencia de los grandes Estados europeos occidentales, Estados Unidos envió una representación de alto rango -el vicepresidente Nelson Rockefellertanto al funeral de Franco como a la proclamación de Juan Carlos I como rey. A principios de 1976 Areilza logró convencer a Henry Kissinger acerca de la necesidad de aprovechar el nuevo acuerdo bilateral para dar una señal decidida de apoyo al monarca español y a las fuerzas políticas emergentes.

Más desafortunado, en relación con el compromiso de la Administración norteamericana con la naciente democracia española, sería el desgraciado comentario del Secretario de Estado, Alexander Haig, al afirmar al día siguiente del frustrado intento de golpe de Estado del 23 de febrero de 1981 que se trataba de «una cuestión interna española». Un gesto que contrasta con el respaldo a la democracia demostrado por los Estados europeos occidentales y la declaración de los propios congresistas norteamericanos apoyando la democracia española y recordando indirectamente el poco oportuno comentario del Secretario de Estado (véase Seregni, 2007: 201-202).

El vínculo establecido con Estados Unidos en los años cincuenta había insertado a España de modo indirecto en el sistema defensivo occidental, de modo que los cambios políticos acaecidos tras la muerte del dictador y los esfuerzos por homologar y normalizar la posición internacional de España 
suscitarían la naturaleza de su anclaje europeo y atlántico, es decir, el dilema de su incorporación a la Alianza Atlántica.

El primer gobierno postfranquista había respaldado la entrada de España en la OTAN, satisfaciendo los deseos de Washington que ya había presionado hacía tiempo en este sentido (véase Chislett, 2005 a). Pero la definición del anclaje atlantista de España se erigiría en una de las cuestiones más polémicas y controvertidas de la política exterior de la joven democracia española, hasta el punto de socavar el consenso entre las fuerzas políticas en este ámbito de la política pública. Tras la difusa política exterior de los Gobiernos de Adolfo Suárez, en los que se coqueteó con la «tercera vía» -el neutralismo de los No-Alineados-, el gobierno de Leopoldo Calvo Sotelo acabaría por solicitar el ingreso a la Alianza Atlántica, proceso que se consumaría el 30 de mayo de 1982, pese a la oposición de la izquierda en el Congreso de los Diputados.

El triunfo del Partido Socialista Obrero Español en las elecciones de 1982 generaría un nuevo escenario, puesto que se había pronunciado en contra de la pertenencia a la Alianza y había defendido en su programa la celebración de un referéndum. El giro pragmatista en la política exterior del gobierno socialista de Felipe González, al hilo de los retos europeos y su conexión con su incardinación atlantista, conduciría, para tranquilidad norteamericana, a una toma de posi- ción favorable a la permanencia en la OTAN en el referéndum celebrado en 1986, que ganaría por estrecho margen y con un gran coste político y moral. Pero el anclaje atlantista se establecería a partir de tres condiciones: España no se integraría en la estructura militar; continuaría la prohibición de almacenar armas nucleares en España; y, por último, la voluntad política de reducir gradualmente la presencia militar de Estados Unidos en España, a tenor del establecimiento de una relación más equilibrada entre Washington y Madrid que fructificaría en el nuevo Convenio de Defensa firmado en diciembre de 1988 -análogo a los firmados por Estados Unidos con otros Estados europeos-.

En el ámbito de los muestreos demoscópicos en torno a la renovación de los acuerdos con Estados Unidos y la adhesión a la OTAN, los datos existentes desde 1969 elaborados por el Instituto de Opinión Pública reflejan un $40 \%$ de los encuestados en desacuerdo con la renovación de los acuerdos bilaterales frente a un $31 \%$ que se pronunciaba de forma favorable. En un encuesta celebrada en 1974, a la misma pregunta, el porcentaje de españoles en contra de la renovación ascendía al $48 \%$ frente a un $16 \%$ a favor. En relación con la adhesión de España a la OTAN, según los datos del Centro de Investigaciones Sociológicas, desde 1978 los que se habían mostrado poco o nada partidarios del ingreso habían pasado de un 15 a un $49 \%$ en 1985 , alcanzando un máximo de un $56 \%$ en 1983 (véase Seregni, 2007: 207). A su 
vez, otros sondeos demoscópicos en los que se valoraban aspectos como el país que más amenazaba la seguridad de España en los años ochenta, mostraban que Estados Unidos, el aliado de España desde los años cincuenta, era valorado como la mayor amenaza (véase Seregni, 2007: 203).

Paradójicamente, los sectores conservadores, tradicionalmente antiamericanos aparecían como aliados de Estados Unidos, no sin matices como se observaría en la abstención de la Alianza Popular en el referéndum, mientras que los sectores más progresistas y radicales, tradicionalmente defensores de los valores democráticos y liberales de Estados Unidos habían ido asumiendo un sentimiento antiamericano a tenor del respaldo de Washington al general Franco. En el discurso de los círculos socialistas y comunistas se desconfiaba del papel de Estados Unidos como generador de libertad y democracia, a la vez que se les identificaba como paradigma del imperialismo, no solo proyectado al ámbito puramente económico sino extensivo a un imperialismo cultural cuya meta era introducir y consolidar el estilo de vida americano -el american way of life-. Así se desprendía explícitamente de los escritos de Manuel Vázquez Montalbán, al considerar a España como una provincia del imperio americano, o de Eduardo Haro Tecglen desde las páginas de Triunfo en 1976, al insistir en la condición imperial de los Estados Unidos.

El pragmatismo que caracterizó la política exterior española durante los gobiernos socialistas de Felipe Gonzá- lez, sólidamente anclada en Europa y en el proceso de construcción europea -especialmente a tenor del entendimiento con Alemania (la República Federal Alemana) y Francia- pero con un fuerte componente atlantista, se iría diluyendo una vez que el Partido Popular y su líder José María Aznar alcanzaron el poder tras las elecciones generales de 1996. Este viraje, que acabaría por quebrar el consenso existente sobre política exterior, nos conduciría a la última de las tesituras históricas que hemos elegido a tenor de otra imagen insular, la reunión celebrada en las Islas Azores entre Bush, Blair y Aznar el 16 de marzo de 2003, en el contexto de las discusiones en el Consejo de Seguridad de las Naciones Unidas sobre Irak. El alineamiento del Gobierno de Aznar, contra los deseos de la inmensa mayoría de la población -en torno al 90\% expresó su oposición a la guerra con Irak en las encuestas-, se hacía, a diferencia de los líderes de las potencias anglosajonas sin someter al Congreso el envío de tropas a Irak. Aznar argumentaba su alineamiento al estar convencido de que "no podemos permanecer por más tiempo en el mismo rincón que los países que no cuentan, que no sirven y que no deciden», para "situar a nuestro país entre los más importantes del mundo cuando el mundo está amenazado debemos asumir responsabilidades y debemos hacerlo con decisión, determinación y liderazgo» (véase Chislett, 2005 a; y Aznar, 2005: 265-274).

Las Azores culminaba el viraje atlantista de la política exterior del Partido 
Popular. Un giro que, no exento de los guiños tradicionales de la política exterior de prestigio de la cultura política conservadora española, pretendía dejar atrás la preponderancia de Alemania y Francia en la política europea de España. Los atentados del 11 de septiembre de 2001 contra Estados Unidos, el inicio de la guerra de Afganistán y posteriormente la guerra de Irak escalonan el progresivo alineamiento de España con Estados Unidos, acogiendo sin reservas cambios doctrinales fundamentales como la «guerra preventiva». Aznar aparecería, incluso, como abanderado de la «Nueva Europa» al ser el principal inductor de un artículo publicado en The Wall Street Journal el 29 de enero de 2003, firmado por los primeros ministros de Portugal, Italia, el Reino Unido, Polonia, Hungría, Dinamarca y la República Checa, alentando la política de la Administración Bush, frente a las cautelas de la "Vieja Europa», en especial Francia y Alemania (véase Seregni, 2007: 263).

La política europea de los Gobiernos de Aznar, determinada exclusivamente por sus preocupaciones domésticas, llevaba a Esther Barbé a caracterizarlas en un artículo bajo el título "pensar locamente, actuar en Europa» (Barbé, 2004: 1). No obstante, William Chislett considera que existían muchos motivos para el compromiso atlantista de Aznar, entre ellos: una relación más estrecha con Estados Unidos y sus más cercanos aliados europeos (el Reino Unido y Portugal) como una forma de contrapeso a la expansión de la Unión Europea hacia el Este; la seguridad en el flanco sur del Mediterráneo; las importantes inversiones española en América Latina; la amplia y creciente presencia hispana en Estados Unidos; y el potencial que suponía la amistad norteamericana para mejorar las relaciones comerciales y emprender nuevos proyectos de inversión (Chislett, 2005 a).

Pero en términos de imagen, de la marca España, en Estados Unidos ¿cuál fue el impacto real de la política de alineamiento atlántico de los Gobiernos de Aznar? William Chislett se planteaba esta cuestión en un artículo publicado en El País el 3 de diciembre de 2005. Pese al potencial de la marca y de la imagen de España en Estados Unidos:

El español es con mucho la lengua extranjera que más se estudia en las escuelas de enseñanza secundaria y en las universidades de EE.UU. España es el tercer país más popular del mundo, tras el Reino Unido e Italia, entre los estudiantes norteamericanos que estudian fuera, y el programa Fullbright para España, iniciado en este país en 1958, es actualmente el tercero más grande del mundo, por presupuesto y número de estudiantes españoles que van a Estados Unidos y de americanos que van a España cada año, tras Alemania y Japón (Chislett, 2005 b).

Pero la grandilocuencia de estos datos no está a la altura del esfuerzo político de los Gobiernos españoles. De hecho, el buque insignia de la diplomacia cultural española, el Instituto Cervantes, contaba en aquel momento 
con un presupuesto global de 60 millones de euros y 42 centros, frente a los 500 millones y 430 centros por todo el mundo del Instituto Francés y la Alliance Française. Una de las consecuencias económicas más preocupantes de la débil imagen de España en Estados Unidos, prosigue el citado autor, es que fuera de las pocas zonas donde el país es bien conocido, sus productos son frecuentemente identificados como procedentes de América Latina y no de Europa. Los datos económicos, que apenas experimentaron variaciones sustanciales durante los gobiernos de Aznar, revelan el bajo perfil de la presencia española en Estados Unidos. El Reino Unido, Alemania, Italia y Francia comercian mucho más. Las exportaciones españolas representan un $0,5 \%$ de las compras exteriores de Estados Unidos, una sexta parte de la cuota del Reino Unido, una cuarta parte de la francesa y una cuarta parte de la italiana.

La impopularidad de la guerra de Irak y los atentados islamistas de Madrid influirían en el desenlace de las elecciones generales de 14 de marzo de 2004. El triunfo del Partido Socialista, bajo el liderazgo de José Luis Rodríguez Zapatero, repercutiría en breve en la retirada de las tropas españolas de Irak, con el consiguiente enojo de la Casa Blanca. La guerra de Irak y el unilateralismo de la Administración Bush incentivaría el antiamericanismo en la opinión pública española.

Las críticas a la intervención en la guerra de Irak, sin el adecuado paraguas legal de las Naciones Unidas y asumiendo la política unilateral de Estados Unidos, quebraba la tradición consolidada en la política exterior de modular la posición española ante las crisis internacionales a tenor de las decisiones adoptadas en los foros multilaterales en los que participa España. Así, la encuesta del 2004 Transatlantic Trend del German Marshall Fund mostraba que España fue el segundo país más reticente en creer que estaba justificado obviar a las Naciones Unidas cuando sus intereses vitales estuvieran en juego (véase Chislett, 2005 a). De hecho, una de las iniciativas centrales de la política exterior del Gobierno de José Luis Rodríguez Zapatero fue la promoción del diálogo entre civilizaciones en el seno de las Naciones Unidas.

La reelección de George Bush en las elecciones presidenciales de 2004 deterioría la imagen de Estados Unidos como paladín de la democracia y las libertades en el mundo y apuntalaría el recelo de los españoles sobre el efecto que tendría sobre la paz y la seguridad en el mundo. El barómetro del Real Instituto Elcano de marzo de 2005 mostraba que el $68 \%$ de las respuestas consideraban el negativo efecto de la continuidad en la Casa Blanca de George Bush a tales efectos. En una encuesta mundial sobre Estados Unidos, en la que participaron una decena de influyentes periódicos de todos los continentes, se ponía de manifiesto que, salvo Israel y Rusia, existía un fuerte rechazo hacia la figura de Bush. Sin embargo, pese a la mala imagen del presidente, los españoles, en concreto 
un $47,3 \%$ de los encuestados, tenía una buena opinión de los ciudadanos norteamericanos. En este sentido, el comportamiento de la opinión pública española es similar al de casi todos los demás Estados europeos, incluido el Reino Unido (Ortega, 2004).

Con este mar de fondo, según los estudios realizados por el Pew Research Center en 2007 y el informe Transatlantic Trends realizado por la German Marshall Fund aquel mismo año, España figuraba como el país europeo -con excepción de Turquía- que sentía menor nivel de cercanía a Estados Unidos -39 en una escala de 0 a 100-. Estos sentimientos pondrían de relieve una ruptura que se comenzaría a vislumbrar a finales de la década de 1990 en la tendencia a una mayor normalización en la percepción y la imagen de Estados Unidos a tenor del mayor equilibrio alcanzado en las relaciones bilaterales y como socios atlánticos durante la década de 1990. Estos datos y la naturaleza del antiamericanismo en España han de llevarnos, por último, a dimensionarlo con el profundo efecto de la modernización en clave de americanización de la sociedad española a lo largo del siglo, especialmente tras la II Guerra Mundial.

\section{AMERICANIZACIÓN Y}

\section{ANTIAMERICANISMO EN LA SOCIEDAD ESPAÑOLA ACTUAL}

El antiamericanismo ha estado determinado en España por la propia naturaleza histórica de las relaciones hispano-norteamericanas y por el emergente papel adquirido por los Estados Unidos, desde la irrupción del poder americano al transitar hacia el siglo XX hasta su encumbramiento hegemónico tras el ciclo de guerras mundiales. Un factor que ha mediatizado, como no podía ser de otro modo, la política exterior y la propia forma de afrontar la modernización de la sociedad española - una cuestión clave en la historia y la propia identidad nacional de España desde el siglo XIX-.

El antiamericanismo español en el curso del siglo XX, como bien subraya Alessandro Seregni, se ha modulado a tenor de dos tradiciones de cultura política, "dos conjuntos (o familias)", que desbordan el propio perímetro de la política: uno referente a la derecha y el otro, a la izquierda. El primero, en el que se integrarían falangistas, nacionalistas, tradicionalistas e integristas católicos y monárquicos, entre otros, se nutriría, en especial durante la dictadura del general Franco, de unos valores en las antípodas de las señas de identidad de los Estados Unidos, tales como el desprecio de la democracia y el liberalismo, aversión hacia el capitalismo, odio hacia el protestantismo o la obsesión antimasónica, además de un nacionalismo herido por la historia común, cuyo punto nodal sería la guerra de 1898. Por su lado, el discurso antiamericano de la izquierda cristalizará básicamente tras la firma del Pacto con Estados Unidos en 1953 y el apoyo dispensado a la dictadura del general Franco. Este se polarizaría 
sobre elementos algunos de ellos ya preexistentes:

(...) había factores que podían contribuir a desarrollar, luego, incidir sobre la evolución del antiamericanismo de izquierda. En este sentido, puede identificarse como impulso primario la generalizada aversión hacia la economía de mercado y el sistema capitalista (...) sostenidos por el pensamiento socialista $y$, de formas diferentes, por la doctrina marxista. Una segunda motivación puede hallarse en la actitud fuertemente hostil y crítica mantenida por los partidos comunistas de los países occidentales con respecto al universo americano (...) Una tercera motivación podríamos encontrarla en las actitudes tercermundista y antiimperialista típicas de una parte de la izquierda, al menos desde los años setenta (Seregni, 2007: 284).

Una realidad cultural y emocional que contrasta vivamente con el intenso proceso de americanización, como clave principal por la que ha transitado la modernización de la sociedad española -como desafío secular-, especialmente desde mediados de siglo $\mathrm{XX}$, aunque los prolegómenos del proceso de americanización hay que buscarlos en el primer tercio del siglo (véase Neila, 2007). La asimilación de las formas culturales, intelectuales, sociales y económicas del proceso de americanización han de matizar, por tanto, las valoraciones que se hacen en torno al antiamericanismo de la sociedad española. César García, profesor de Comunicación en la Universidad Estatal del Estado de Washington, indaga precisamente sobre la fascinación y la adopción del estilo de vida y la cultura popular estadounidenses, manifiesto en las formas de ocio -caso de la presencia y aceptación del cine norteamericano o las series de televisión-, en el terreno empresarial y laboral. Estados Unidos sigue siendo el primer destino de formación en el extranjero de los hijos de las familias pudientes o el impacto de las marcas como Microsoft, Coca Cola o Google entre los españoles- y en la adopción de pautas sociológicas, como la modificación en la ética del trabajo en los últimos treinta años. En conclusión, recurriendo a las palabras de César García, los españoles:

(...) simplemente no somos antinorteamericanos ni en nuestra forma de vida ni en nuestros gustos, ni en nuestros valores ni en nuestras aspiraciones. Lo que es cierto es que las escasas manifestaciones de casticismo que han pervivido en nuestra sociedad -y aún resultan políticamente correctas- se producen únicamente cuando lo genuinamente español se contrapone a la idea de lo norteamericano (García, C., 2007).

\section{BIBLIOGRAFÍA}

Aznar, José María (2005) Retratos y perfiles, Barcelona, Planeta.

Balfour, Sebastián y Paul Preston, (eds.) (2002), España y las grandes potencias en el siglo XX, Barcelona, Crítica.

Barbé, Esther (2004), «Pensar locamente, actuar en Europa», en Barbé, E. (coord.) España en Europa 1996-2004, Barcelona, 
José Luis Neila • Entre Cuba y las Azores...

Institut Universitari d'Estudis Europeus, pp.1-3.

Chislett, William (2005a) «El antiamericanismo en España: el peso de la historia», Documento de Trabajo 47/2005, Boletín del Real Instituto Elcano de Estudios Internacionales y Estratégicos.

Chislett, William (2005b), «El bajo perfil de España en Estados Unidos», El País, 3 de diciembre de 2005.

Lamo de Espinosa, Emilio (1993) «La mirada del otro. La imagen de España en el extranjero", en Información Comercial Española, n. 722, pp. 11-25.

Lamo de Espinosa, Emilio (2001) «La normalización de España», en Claves de razón práctica, n. 111, pp. 4-16.

Elordi, Carlos (2003), El amigo americano. De Franco a Aznar: una adhesión inquebrantable, Madrid, Temas de Hoy.

García, César (2007), «El antiamericanismo en España", $A B C, 14$ de noviembre.

Hayes, Carlton J.H. (1946), Misión de guerra en España, Buenos Aires, Epesa.

Huntington, Samuel (2005), El choque de civilizaciones y la reconfiguración del orden mundial, Barcelona, Paidós.

Isbell, Paul (2001), «Excepcionalidad española y excepcionalismo estadounidense: raíces de desencuentros y reencuentros", en Flys Junquera, C., y J.E. Cruz Cabrera, (eds.) El nuevo horizonte: España/Estados Unidos. El legado de 1898 y 1898 frente al nuevo milenio, Alcalá de Henares, Universidad de Alcalá de Henares, pp. 47-54.

Mignolo, Walter D. (2003), Historias locales/ diseños globales. Colonialidad, conocimientos subalternos y pensamiento fronterizo, Madrid, Akal.

Montero, José Antonio (2004), «Las relaciones hispano-norteamericanas en los años de la Primera Guerra Mundial, en Cuadernos de Historia Contemporánea, vol. 26, Madrid, Universidad Complutense, pp. 23-47.

Neila, José Luis (2007), «España y la emergencia de poder americano, 1902-1936», en Temas de Historia Argentina y Americana, n. 10, Buenos Aires, pp. 145-185.
Niño, Antonio (2003), «50 años de relaciones entre España y Estados Unidos», en Cuadernos de Historia Contemporánea, v. 25, pp. 9-33.

Niño, Antonio (2005), «Las relaciones culturales como punto de reencuentro hispanoestadounidense», en Delgado, L- María Dolores Elizalde, (eds.) España y Estados Unidos en el siglo XX, Madrid, Consejo Superior de Investigaciones Científicas, pp. 57-94.

Núñez Florencio, Rafael (2001), Sol y sangre. La imagen de España en el mundo, Madrid, Espasa.

Ortega, Andrés (2004), «El rechazo a Bush contrasta con la simpatía a EE UU», El País, 15 de octubre.

Pardo, Rosa (2003), «La política norteamericana", en Portero, Florentino (ed.) «Dossier. La política exterior de España en el siglo XX», en Ayer, n. 49, pp. 13-53.

Payne, Stanley G. (2003), «Los Estados Unidos y España: percepciones, imágenes e intereses", en Cuadernos de Historia Contemporánea, n.25, pp. 155-167.

Stabler, W. (1987), "The View from the Embassy», en Binnendijk, Hans (ed.) Authoritarian Regimes in Transition, Centre for the Study of Foreign Affairs, US Departament of State.

Quintana Navarro, Francisco (1998), «España en la política europea contemporánea: ¿secular aislamiento o acomodo circunstancial?", en Asociaçao Portuguesa de Historia das Relaçoes Internacioniais - Comisión Española de Historia de las Relaciones Internacionales (eds.), I Encuentro Peninsular de Historia de las relaciones internacionales, Zamora, Ministerio de Asuntos Exteriores, Fundación Rei Afonso Henriques, Banco Espirito Santo, pp. 219-244.

Sánchez Mantero, Rafael (1998), «El 98 y la imagen de España en los Estados Unidos», en Revista de Occidente, n. 202-203, pp. 294-309.

Seregni, Alessandro (2007), El antiamericanismo español, Madrid, Síntesis. 
Ucelay-Da Cal, Enric (1992), «La imagen internacional de España en el período de entreguerras: reminiscencias, estereotipos, dramatización neorromántica y sus consecuencias historiográficas», en Spagna Contemporánea, n. 15, pp. 23-52.
Vázquez Montalbán, Manuel (1974), La penetración americana en España, Madrid, Edicusa.

Vázquez Montalbán, Manuel (1976), ¿Qué es el imperialismo?, Barcelona, La Gaya Ciencia. 